\title{
Nesfatin-1 Ameliorates Testicular Function Changes in Type 2 Diabetic Rats
}

\author{
KHALED A.A. ABULFADLE, M.D. and SAMA S. KHALIL, M.D. \\ The Department of Physiology, Faculty of Medicine, Zagazig University, Zagazig, Egypt
}

\begin{abstract}
Background: Type 2 Diabetes Mellitus (T2DM) is a common problem that is accompanied by disturbed metabolic homeostasis, oxidative stress and increase in proinflammatory cytokines. On the other hand, normal body metabolism is essential for the testicular function. Also, nesfatin-1 is a peptide hormone produced by numerous tissues, including the testes and shared in regulation of metabolic homeostasis and had antioxidant and anti-inflammatory properties.
\end{abstract}

Aim: To investigate the effects of T2DM on testicular functions and the effects of exogenous treatment with nesfatin1 on modulation of those effects, and, to declare the possible involved mechanisms.

Material and Methods: 24-healthy adult male albino rats with a weight of $180-200 \mathrm{gm}$, were divided into three groups of 8 rats each; control, type 2 diabetic (T2DM) and nesfatin1 treated type 2 diabetic (T2DM + Nesfatin) groups. The control group received a standard diet, while, the diabetic groups (T2DM and T2DM + Nesfatin) received a High Fat Diet (HFD). Five weeks after beginning HFD, rats were fasted for $12 \mathrm{~h}$ and received streptozotocin, in a dose of $35 \mathrm{mg} / \mathrm{kg}$, dissolved in $0.1 \mathrm{M}$ sodium citrate buffer $(\mathrm{pH} \mathrm{4.5)}$ intraperitoneally (i.p.). Then, rats of the control and T2DM groups received normal saline i.p. in a dose of $1 \mathrm{ml} / \mathrm{kg} /$ day for more 4 weeks and they continued to be fed with their corresponding diet, while, those of T2DM + Nesfatin group were treated with nesfatin-1 in a dose of $2 \mathrm{~g} / \mathrm{g} /$ day i.p. for more 4 weeks and they continued to be fed with HFD. The serum levels of testosterone, Follicle Stimulating Hormone (FSH), Luteinizing Hormone (LH), tumor necrosis factor alpha (TNF $\alpha)$ and interleukin-1 beta (IL-1 $\beta$ ) were measured in the studied groups. Also, epididymal sperm motility and count, testicular histopathology and antioxidant enzymes Superoxide Dismutase (SOD) and catalase (CAT) activities were examined.

Results: A significant $(p<0.001)$ increase in the final Body Mass Index (BMI), Homeostasis Model Assessment-Insulin Resistance (HOMA-IR) index, serum levels of glucose, insulin, Total Cholesterol (TC), Triglycerides (TG), Low Density Lipoprotein (LDL), TNF $\alpha$ and IL-1 $\beta$ was found in the T2DM group in comparison to the control group. On the other hand, a significant $(p<0.001)$ decrease in serum levels of High Density Lipoprotein (HDL), FSH, LH, and testosterone was

Correspondence to: Dr. Khaled A.A. Abulfadle, E-Mail: khafadle@gmail.com reported in T2DM group in comparison to the control group. Also, a significant $(p<0.001)$ decline in right testis weight, testicular SOD and CAT activity, and, epididymal sperm motility and count was found in T2DM group in comparison to the control group. Also, in T2DM group, a significant negative correlation between testicular functions (serum testosterone, epididymal sperm count and epididymal sperm motility) and each of final BMI, HOMA-IR, serum levels of IL-1 $\beta$ and TNF $\alpha$, and, testicular SOD and CAT activity, was reported. After exogenous nesfatin-1 treatment, the changes noticed in T2DM group were reversed as a significant $(p<0.001)$ decrease in final BMI, HOMA-IR index, serum levels of glucose, insulin, TC, TG, TNF $\alpha$ and IL-1 $\beta$ was found in the T2DM+Nesfatin group in comparison to the T2DM group. On the other hand, a significant $(p<0.001)$ increase in serum levels of HDL, FSH, LH, and testosterone in the T2DM + Nesfatin group was recorded in comparison to the T2DM group. Also, a significant $(p<0.001)$ rise in right testis weight, testicular SOD and CAT activity, and, epididymal sperm motility and count was found in the T2DM + Nesfatin group when compared with T2DM group.

Conclusion: T2DM decreased testicular functions, spermatogenesis and steroidogenesis, through disturbing metabolic homeostasis, decreasing the gonadotropins secretion, reducing testicular antioxidant activity and increasing proinflammatory cytokines. On the other hand, exogenous nesfatin- 1 treatment ameliorated testicular function changes in T2DM through controlling body weight, improving metabolic disturbances, increasing FSH and LH secretion, its antioxidant and its antiinflammatory properties.

Key Words: Type 2 diabetes mellitus - Male albino rats Nesfatin-1 - Testicular function - Oxidative stress - Proinflammatory cytokines.

\section{Introduction}

NESFATIN-1 is anorexigenic peptide that was first identified in 2006 and has been related to the regulation of appetite and loss of weight [1]. It is a peptide formed of 82 amino acids originated from its precursor protein, nucleobindin-2 (NUCB2) which by post-translational modification produced nesfatin-1, nesfatin-2, and nesfatin-3 [2] Injection of nesfatin-1, but not of nesfatin-2 or nesfatin-3, inhibited food intake, whereas blockade 
of its actions increased feeding in adult rats [3] Nesfatin- 1 was identified in the hypothalamus, pituitary, spinal cord cardiac autonomic nuclei and in other tissues including gastric mucosa, adipocytes, pancreatic beta cells and gonads [4] Nesfatin-1 has the capacity to cross the blood brain barrier [5]. Also, there was evidence indicating that nesfatin-1 stimulated glucose-induced insulin release, et al., [6]. Shimizu, Tanaka, et al., [7] found that nesfatin-1 intravenous administration significantly decreased blood glucose levels in hyperglycemic mice. On the other hand, Ramanjaneya, Chen, et al., [8] reported that high-fat fed diet mice had increased circulating levels of nesfatin-1. Also, Zhang, Li, et al., [9] have shown that Nesfatin- 1 plasma levels were increased in type 2 diabetic patients. On the contrary, Khalili, Khaniani, et al., [6] reported a decrease in Nesfatin-1 plasma levels in T2DM which was a cause of diabetic hyperphagia. Also, Yang, Zhang, et al., [10] and Xia, Liang, et al., [5] declared that changed Nesfatin1 levels in Type 2 Diabetes Mellitus (T2DM) were accompanied with impaired glucose tolerance, Body Mass Index (BMI) and fasting blood glucose. Moreover, Wu, Yang [11] have reported that Nesfatin-1 raised peripheral and hepatic sensitivity of insulin, through raising peripheral uptake of glucose and inhibition of gluconeogenesis. Reproduction is controlled by regulatory signals that integrated at the Hypothalamic-Pituitary-Gonadal (HPG) axis and the gonadal function is regulated by gonadotropins, and locally originated signals [12]. Among its main external regulators, the HPG axis function is gated metabolically, and the disturbances of body energy homeostasis, ranging from anorexia to obesity, were known to affect gonadal function [13]. Diabetes mellitus a common chronic metabolic disease that is manifested by hyperglycemia and is caused by either abnormal insulin production, insulin resistance or often both [14]. Alves, Martins, et al., [15] reported that diabetic patients may experience some sexual abnormalities such as impotence, sexual dysfunction, and infertility. Nah, Koh, et al., [16] found a reduction in Follicle Stimulating Hormone (FSH), Luteinizing Hormone (LH) and testosterone serum levels with a decline in sperm motility and count in diabetes. On the contrary, Idris, Budin [17] reported insignificant changes in FSH, LH and testosterone serum levels in diabetes, while, Agbaje, Rogers, et al., [18] declared that diabetic patients had increased sperm nuclear and mitochondrial DNAs damage, although, they may show normal semen parameters. GarcíaGaliano, Navarro, et al., [4] reported that nesfatin1 participated in the control of LH and FSH secretion. Also, García-Galiano, Pineda, et al., [19] confirmed that Nesfatin-1 is a part of the HPG axis and involved in gonadal functions and reproduction as they confirmed that NUCB2 mRNA had been found in rat and human testes where Sertoli and Leydig cells had Nesfatin- 1 immunoreactivity. From the previously discussed information, it was clear that data about the effect of diabetes on testicular function was contradictory. Also, it was obvious that Nesfatin-1 was expressed in rat testis and had a relation to its function. Moreover, it was identified that nesfatin- 1 can improve T2DM. Thus, this study was done to identify the effects of T2DM on rat testicular functions and to examine the effects of exogenous treatment with Nesfatin- 1 on modulation of these effects. Testosterone, FSH, LH, tumor necrosis factor alpha (TNF ct) and interleukin1 beta (IL-1 (3) serum levels were estimated in the studied groups. Also, epididymal sperm motility and count, both testicular antioxidant enzyme activity and histopathology were assessed to declare the mechanisms probably involved.

\section{Material and Methods}

This study was done in Physiology Department of Zagazig Faculty of Medicine, between November 2017 and January 2018.

\section{Experimental design:}

24-healthy adult male albino rats with a weight of 180-200gm, were obtained from the Animal House of Zagazig Faculty of Medicine. Under hygienic conditions, rats were kept (4 per each steel wire cage) in the Physiology Animal House of Zagazig Faculty of Medicine. They had water free access at room temperature and with $12 \mathrm{~h}$ light/dark cycle maintenance. After an adaptation period of one week, rats were divided into three groups of 8 rats each; control, type 2 diabetic (T2DM) and nesfatin- 1 treated type 2 diabetic (T2DM + Nesfatin) groups. The control group received a standard diet which consisted of carbohydrate $(62.8 \%)$, protein $(25.8 \%)$ and fat $(11.4 \%)$, while, the diabetic groups (T2DM and T2DM + Nesfatin) received a High Fat Diet (HFD) which composed of standard diet $(72.8 \%)$, cholesterol (2\%), lard (25\%) and bile salts (0.2\%) [20]. Five weeks after beginning HFD, rats were fasted for $12 \mathrm{~h}$ and received streptozotocin (STZ, SigmaAldrich, USA), in a dose of $35 \mathrm{mg} / \mathrm{kg}$, dissolved in $0.1 \mathrm{M}$ sodium citrate buffer $(\mathrm{pH} 4.5)$ intraperitoneally (i.p.) [21]. The control group (standard diet fed) received the vehicle sodium citrate buffer i.p. in a dose of $1 \mathrm{ml} / \mathrm{kg}$. Three days after STZ injection, fasting blood glucose was estimated after $12 \mathrm{~h}$ fasting with ACCU-CHEK one-touch glucose auto analyzer (Germany) from the tail vein. Rats were 
considered diabetic when blood glucose levels were above $250 \mathrm{mg} / \mathrm{dl}$ [22]. Rats of the control and T2DM groups received normal saline i.p. in a dose of $1 \mathrm{ml} / \mathrm{kg} /$ day for more 4 weeks and they continued to be fed with their corresponding diet, while, those of T2DM + Nesfatin group were treated with Nesfatin-1 in a dose of $2 \mathrm{~g} / \mathrm{k} /$ day i.p. [23] for more 4 weeks [total time 9 weeks $(5+4)$ ] and fed with HFD. Nesfatin-1 was obtained from Sigma-Aldrich, USA (Cat. No. SRP3291).

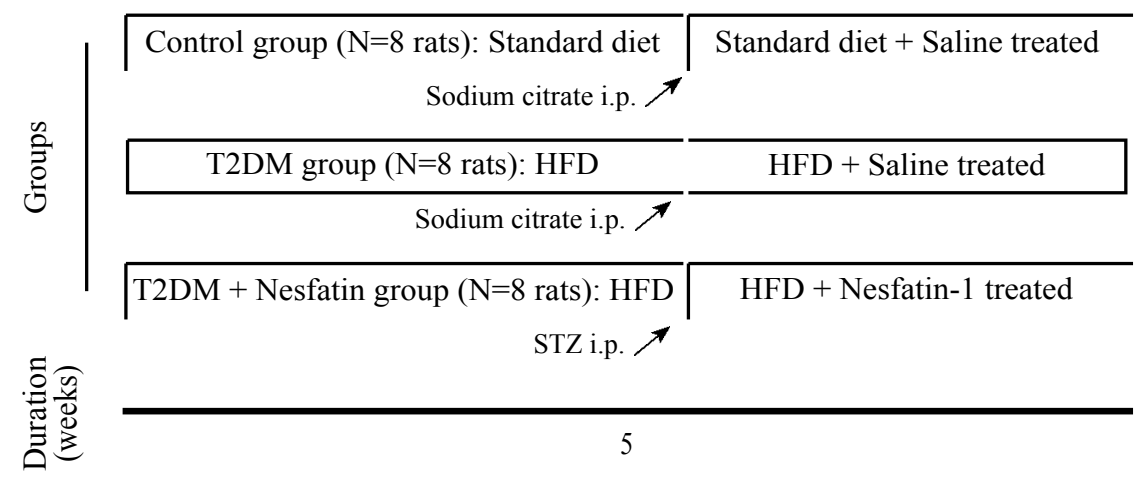

Fig. (1): Design of the experiment.

$24 \mathrm{~h}$ after the last injection of Nesfatin- 1, samples of blood were obtained from retro-orbital venous plexus and centrifugated at 3000rpm for 20 min to separate the serum [24] which was kept frozen at $\left(20^{\circ} \mathrm{C}\right)$ until used to measure serum glucose, insulin, Total Cholesterol (TC), Triglyceride (TG), High Density Lipoproteins cholesterol (HDL), TNF $\alpha$, IL-1 $\beta$, LH, FSH and testosterone levels. FSH, LH and testosterone were estimated in serum using commercial kits from Biocompare.com (Cat. No. LS-F6305-1, LS-F27508-1 and LS-F10018-1, respectively). Also, glucose, insulin, TC, TG and HDL serum levels were measured using commercial kits from Sigma-Aldrich, USA (Cat. No. GAGO20, RAB0904, MAK043, TR0100 and MAK045, respectively), while, Low Density Lipoprotein-cholesterol (LDL) serum level was calculated using Friedewald formula:

$$
\mathrm{LDL}(\mathrm{mg} / \mathrm{dl})=(\mathrm{TC})-\left[(\mathrm{HDL})+\left(\frac{\mathrm{TG}}{5}\right)\right][25]
$$

For assessing Insulin Resistance (IR), the Homeostasis Model Assessment-IR (HOMA-IR) index was calculated by:

$$
\text { HOMA-IR }=\frac{\begin{array}{c}
\text { Fasting glucose }(\mathrm{mg} / \mathrm{dl}) \mathrm{X} \\
\text { fasting insulin }(\mathrm{U} / \mathrm{ml})
\end{array}}{405}
$$

Palasz, Janas-Kozik [27] confirmed that the more the HOMA-IR, the more insulin resistance and vice versa. For measuring serum levels of the proinflammatory cytokines, TNF $\alpha$ and IL- $1 \beta$, commercial kits from Sigma-Aldrich, USA (Cat. No. RAB0480 and RAB0277, respectively), were used. After collection of the blood, rats were killed by decapitation, laparotomy was done, and the right testes from the different groups were removed and weighed, then, histopathologically examined. Tunica vaginalis was discarded and the testes were dissected out and to remove blood and the adherent tissues, they were cleaned with a cold physiological saline. The samples were fixed in $10 \%$ formaldehyde, embedded in paraffin wax, sectioned at $5 \mathbf{m}$ thickness, and stained with hematoxylin and eosin. Under a light microscope, the sections were examined and the general histological features were assessed. The left testes were sliced and in cold $50 \mathrm{mM}$ phosphate buffer $(\mathrm{pH} 7.0)$ containing $0.1 \mathrm{mM}$ EDTA they were homogenized to give a $10 \%$ homogenate $(\mathrm{w} / \mathrm{v})$ which was centrifuged at 1000 rpm for 10min giving a supernatant which was used for Superoxide Dismutase (SOD) and catalase (CAT) activity assays [28] by a colorimetric method using commercial kits obtained from abcam.com (product code ab65354 and ab83464, respectively). For studying the epididymal sperm parameters, the epididymis was separated from the testis carefully and in $1 \mathrm{ml}$ of phosphate buffered saline $(\mathrm{pH} \mathrm{7.2)}$, it was minced to have a suspension [29] in which the sperm count was assessed as per the standard method in Neubauer's chamber [30]. Briefly, in leukocyte hemocytometer, a part from the suspension (up to 0.5) was taken and then, up to the mark 11 it was diluted with phosphate buffered saline. The suspension was mixed well and applied into Neubauer's counting chamber. Under the light microscope at $400 \mathrm{X}$, the total sperm count in $8_{2}$ squares except the central erythrocyte area of $1 \mathrm{~mm}$ each was determined and multiplied by $5 \times 10^{4}$ to express the number of spermatozoa $/ \mathrm{ml}$. The sperm motility percentage was determined by dividing the number of motile sperm cells over the total number of sperm cells (motile and non-motile) 
where the sperm cells that displayed some movement were considered as motile sperm cells, while those which were not moving were considered as non-motile sperm cells [31]. For comparing the final BMI $\left(\mathrm{gm} / \mathrm{cm}^{2}\right)$ among the different groups, it was calculated just before rats were killed (under ether anesthesia), by dividing body weight ( $\mathrm{gm}$ ) on length ${ }^{2}\left(\mathrm{~cm}^{2}\right)$ where rat length was estimated by measuring the distance between the anus and the nose [32]

\section{Statistical analysis:}

The data obtained was expressed as mean \pm standard error of the mean (mean \pm SEM). By the use of IBM SPSS Statistics (Version 25 Software for Windows), means were compared by one-way analysis of variance (ANOVA) and Tukey HSD for Post hoc Multiple Comparisons for statistical significance. Also, by the use of Graph Pad Prism (Version 7 Software for Windows), correlation analysis was achieved to investigate the association between some biochemical and testicular parameters within the T2DM group. $p$-value $\leq 0.05$ represented statistical significance.

\section{Results}

Table (1) clarified the biochemical changes among the different studied groups. In the T2DM group, a significant $(p<0.001)$ increase in final BMI, HOMA-IR index, serum levels of glucose, insulin, TC, TG, LDL, TNF $\alpha$ and IL- $1 \beta$, was found in comparison to the control group. On the other hand, a significant $(p<0.001)$ decrease in serum levels of HDL, FSH, LH, and testosterone was reported in T2DM group in comparison to the control group. Also, a significant $(p<0.001)$ decline in right testis weight, testicular SOD and CAT activity, and, epididymal sperm count and motility was recorded in T2DM group in comparison to the control group. In T2DM + Nesfatin group, a significant $(p<0.001)$ decrease in final BMI, HOMAIR index, serum levels of glucose, insulin, TC, TG, $\mathrm{TNF} \alpha$ and IL- $1 \beta$ was found in comparison to the T2DM group. On the other hand, a significant ( $p$ $<0.001$ ) increase in serum levels of HDL, FSH, $\mathrm{LH}$, and testosterone was identified in T2DM + Nesfatin group in comparison to the T2DM group. Also, a significant $(p<0.001)$ rise in right testis weight, testicular SOD and CAT activity, and, epididymal sperm count and motility was reported in T2DM + Nesfatin group in comparison to the T2DM group. In comparison to the control group, a significant $(p<0.001)$ increase in final BMI, HOMA-IR index, serum levels of glucose, insulin,
TC, TG, LDL and IL- $1 \beta$ was found in the T2DM + Nesfatin group. Also, a significant $(p<0.001)$ rise in serum level of TNF $\alpha$ was reported in the $\mathrm{T} 2 \mathrm{DM}+$ Nesfatin group. On the other hand, a significant $(p<0.001)$ decrease in serum levels of HDL, FSH, LH, and testosterone was declared in $\mathrm{T} 2 \mathrm{DM}+$ Nesfatin group in comparison to the control group. Also, a significant $(p<0.001)$ decline in right testis weight, testicular SOD and CAT activity, and, epididymal sperm count and motility was found in T2DM + Nesfatin group in comparison to the control group.

On the other hand, in T2DM group (Table 2), a significant negative correlation was noticed between final BMI and each of serum testosterone ( $r=-0.95, p<0.001)$, epididymal sperm count $(r=$ $-0.9, p<0.01)$ and epididymal sperm motility ( $r=$ $0.9, p<0.01)$. Also, HOMA-IR was negatively correlated to each of serum testosterone $(r=-0.81$, $p<0.05)$, epididymal sperm count $(r=-0.95, p$ $<0.001)$ and epididymal sperm motility $(r=-0.78$, $p<0.05$ ). Moreover, a significant negative correlation was seen between serum level of IL- $1 \beta$ and each of serum testosterone $(r=-0.93, p<0.001)$, epididymal sperm count $(r=-0.88, p<0.01)$ and epididymal sperm motility $(r=-0.91, p<0.01)$. Furthermore, serum TNF $\alpha$ level was negatively associated with each of serum testosterone ( $r=$ $-0.72, p<0.05)$, epididymal sperm count ( $r=-0.81$, $p<0.05)$ and epididymal sperm motility $(r=-0.77$, $p<0.05)$. On the other hand, in the same studied group, a significant positive correlation was found between testicular SOD activity and each of serum testosterone $(r=0.97, p<0.0001)$, epididymal sperm count $(r=0.97, p<0.0001)$ and epididymal sperm motility ( $r=0.96, p<0.001)$. Also, testicular CAT activity was positively associated with each of serum testosterone $(r=0.94, p<0.001)$, epididymal sperm count $(r=0.85, p<0.01)$ and epididymal sperm motility $(r=0.84, p<0.01)$.

On histopathological examination of rat testicular tissue in the different groups Fig. (2), there was a normal seminiferous tubule formed of normal spermatogenic cells layers with central mature sperms and surrounded by a basement membrane which was thin in the control group. On the other hand, in T2DM group, there was a decrease in both, the number of spermatogenic cells layers and the mature sperms while, the basement membrane was thick, but, in T2DM + Nesfatin group, there was a seminiferous tubule with marked improvement in; the number of spermatogenic cells layers, the mature sperms number and the basement membrane thickness. 

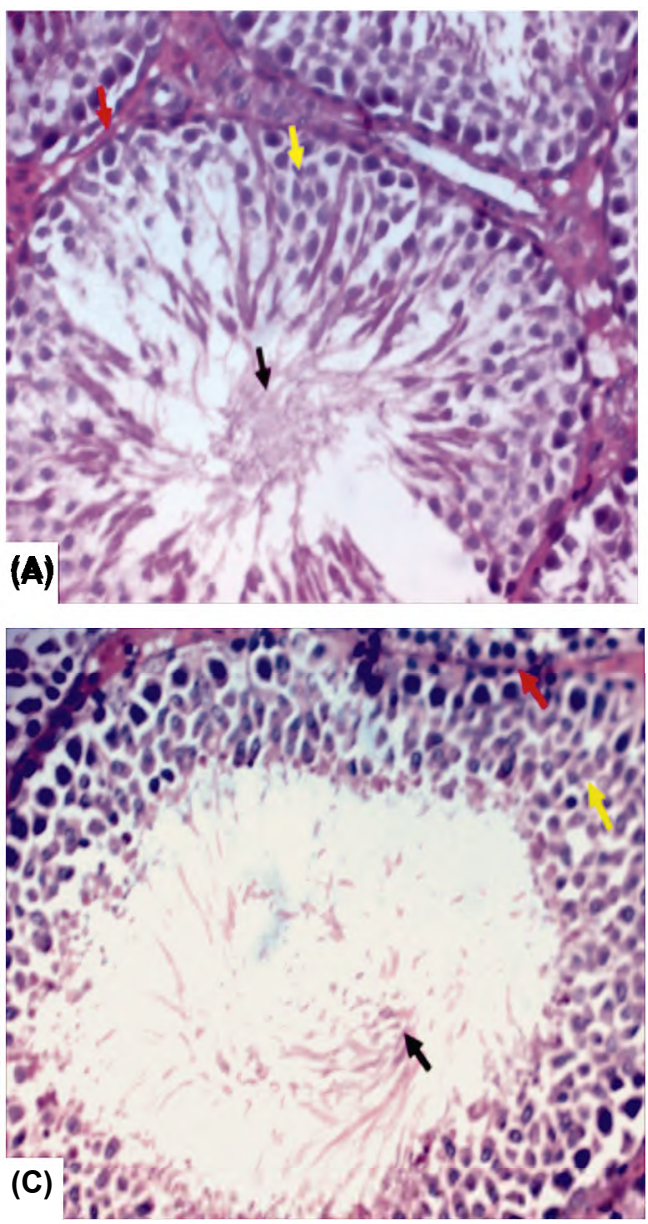

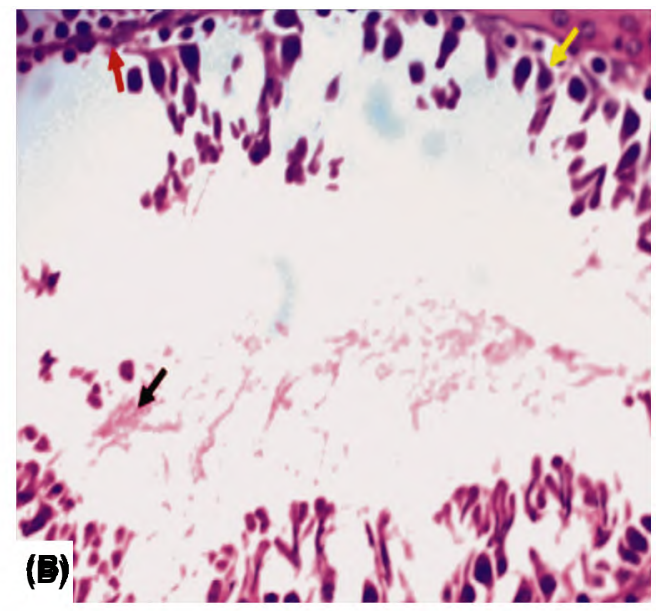

Fig. (2): Photomicrograph of testicular tissue of rats in the control Group (A), T2DM Group (B) and T2DM + Nesfatin Group (C) (Hematoxylin and Eosin X400). In control group, it showed normal seminiferous tubule formed of normal layers of spermatogenic cells (yellow arrow) with central mature sperms (black arrow) and surrounded by a thin basement membrane (red arrow). In T2DM group, it showed a decrease in both, the number of layers of spermatogenic cells (yellow arrow) and the mature sperms (black arrow) and the basement membrane was thick (red arrow). In T2DM + Nesfatin group, it showed a seminiferous tubule with marked improvement in; the number of layers of spermatogenic cells (yellow arrow), the number of mature sperms (black arrow) and the thickness of the surrounding basement membrane (red arrow).

Table (1): Biochemical changes among different groups.

\begin{tabular}{|c|c|c|c|}
\hline & Control & T2DM & T2DM + Nesfatin \\
\hline Final BMI $\left(\mathrm{gm} / \mathrm{cm}^{2}\right)$ & $0.56 \pm 0.01$ & $0.81 \pm 0.01^{\mathrm{a}}$ & $0.69 \pm 0.01 \mathrm{a}, \mathrm{b}$ \\
\hline Serum glucose (mg/dl) & $86.13 \pm 1.23$ & $294.88 \pm 4.39^{\mathrm{a}}$ & $132 \pm 3.24^{\mathrm{a}^{\circ} \mathrm{b}}$ \\
\hline Serum insulin ( & $22.86 \pm 0.44$ & $35.04 \pm 0.41^{\mathrm{a}}$ & $27.44 \pm 0.29^{a^{\prime} b}$ \\
\hline HOMA-IR & $4.86 \pm 0.1$ & $25.53 \pm 0.57^{\mathrm{a}}$ & $8.95 \pm 0.24^{\mathrm{a}^{\circ} \mathrm{b}}$ \\
\hline Serum TC (mg/dl) & $84.4 \pm 1.59$ & $177.89 \pm 2.16 \mathrm{a}$ & $157.25 \pm 2.28^{\mathrm{a}^{\prime} \mathrm{b}}$ \\
\hline Serum HDL (mg/dl) & $39.06 \pm 0.58$ & $25.34 \pm 0.72^{\mathrm{a}}$ & $32.67 \pm 0.92^{\mathrm{a}^{\prime} \mathrm{b}}$ \\
\hline Serum TG (mg/dl) & $66.68 \pm 0.38$ & $115.96 \pm 0.55^{\mathrm{a}}$ & $79.95 \pm 0.61 \mathrm{a}, \mathrm{b}$ \\
\hline Serum LDL (mg/dl) & $32.38 \pm 1.95$ & $114.95 \pm 14.47 \mathrm{a}$ & $112.82 \pm 3.46^{\mathrm{a}}$ \\
\hline Serum TNF $\alpha(\mathrm{pg} / \mathrm{dl})$ & $5.8 \pm 0.05$ & $12.17 \pm 0.09^{\mathrm{a}}$ & $6.18 \pm 0.04^{b^{\prime} c}$ \\
\hline Serum IL-1 $\beta(\mathrm{pg} / \mathrm{ml})$ & $36.96 \pm 0.21$ & $64.45 \pm 0.26^{\mathrm{a}}$ & $50.32 \pm 0.21 \mathrm{a}, \mathrm{b}$ \\
\hline Serum FSH (ng/ml) & $6.41 \pm 0.1$ & $4.13 \pm 0.04^{\mathrm{a}}$ & $5.31 \pm 0.04 \mathrm{a}^{\circ} \mathrm{b}$ \\
\hline Serum LH (ng/ml) & $6.22 \pm 0.05$ & $4.15 \pm 0.03^{\mathrm{a}}$ & $5.56 \pm 0.08^{\mathrm{a}^{\mathrm{b}} \mathrm{b}}$ \\
\hline Serum Testosterone (ng/ml) & $4.31 \pm 0.02$ & $2.41 \pm 0.04^{\mathrm{a}}$ & $3.98 \pm 0.03 \mathrm{a}, \mathrm{b}$ \\
\hline Right testis weight (gm) & $1.45 \pm 0.02$ & $0.97 \pm 0.03^{\mathrm{a}}$ & $1.28 \pm 0.01 \mathrm{a}, \mathrm{b}$ \\
\hline Testicular SOD activity (U/mg protein) & $81.36 \pm 0.27$ & $42.39 \pm 0.49^{\mathrm{a}}$ & $73.29 \pm 0.57^{a^{\prime} b}$ \\
\hline Testicular CAT activity (U/mg protein) & $24.36 \pm 0.36$ & $8.81 \pm 0.17^{\mathrm{a}}$ & $19.89 \pm 0.29^{a^{\prime} b}$ \\
\hline Epididymal sperm count (millions/ml) & $47.25 \pm 0.38$ & $33.09 \pm 0.44^{\mathrm{a}}$ & $37.74 \pm 0.29^{a} \cdot b$ \\
\hline Epididymal sperm motility (\%) & $67.55 \pm 0.22$ & $41.05 \pm 0.21 \mathrm{a}$ & $58.06 \pm 0.58 \mathrm{a}, \mathrm{b}$ \\
\hline
\end{tabular}

Data was expressed as Mean \pm SEM.

$a: p<0.001$ in comparison with the control group.

$b: p<0.001$ in comparison to the T2DM group.

$c: p=0.01$ in comparison to the control group. 
Table (2): Pearson's correlation coefficient ( $r$ ) between some biochemical and testicular parameters within T2DM group.

\begin{tabular}{|c|c|c|c|c|c|c|}
\hline \multirow{3}{*}{ Correlation } & \multicolumn{6}{|c|}{ T2DM group } \\
\hline & \multicolumn{2}{|c|}{$\begin{array}{c}\text { Serum } \\
\text { testosterone }\end{array}$} & \multicolumn{2}{|c|}{$\begin{array}{l}\text { Epididymal } \\
\text { sperm count }\end{array}$} & \multicolumn{2}{|c|}{$\begin{array}{c}\text { Epididymal } \\
\text { sperm motility }\end{array}$} \\
\hline & $r$ & $p$ & $r$ & $p$ & $r$ & $p$ \\
\hline Final BMI & -0.95 & $<0.001$ & -0.9 & $<0.01$ & -0.9 & $<0.01$ \\
\hline HOMA-IR & -0.81 & $<0.05$ & -0.95 & $<0.001$ & -0.78 & $<0.05$ \\
\hline Serum IL-1 a & -0.93 & $<0.001$ & -0.88 & $<0.01$ & -0.91 & $<0.01$ \\
\hline Serum TNF 3 & -0.72 & $<0.05$ & -0.81 & $<0.05$ & -0.77 & $<0.05$ \\
\hline Testicular SOD activity & 0.97 & $<0.0001$ & 0.97 & $<0.0001$ & 0.96 & $<0.001$ \\
\hline Testicular CAT activity & 0.94 & $<0.001$ & 0.85 & $<0.01$ & 0.84 & $<0.01$ \\
\hline
\end{tabular}

$p<0.05$ indicated statistical significance.

\section{Discussion}

This study was done to know the possible effects of T2DM on testicular function in male albino rats and to examine the effect of exogenous nesfatin1 treatment on diabetic rat testicular function. To achieve this, a rat model of T2DM was used in which rats fed HFD for five weeks and then, they were given a single small dose of STZ as discussed earlier. Also, testosterone serum levels, epididymal sperm motility and count were used as indicators for testicular function. In the T2DM group, a significant increase in final BMI, HOMA-IR index as well as glucose, insulin, TC, TG and LDL serum levels, was found in comparison to the control group, but, a significant decrease in serum levels of HDL was recorded in T2DM group when compared with the control one. These results confirmed incidence of T2DM which was supported by Mahdieh, et al., [33] who reported a significant increase in BMI in T2DM and they owed this to diabetic hyperphagia that was accompanied by a decline in fasting plasma nesfatin-1 / NUCB2. Also, Nazircglu, et al., [34] reported increased insulin resistance and disturbed lipid profile in cases of T2DM. On the other hand, a significant decrease in testosterone serum levels, right testis weight, epididymal sperm motility and count was reported in T2DM group when compared with the control one. These results were in line with Kim and Moley [35] who recorded a significant decline in steroidogenic genes expression in diabetic cases. Also, in agreement with the results of the current study, Hamden, Jaouadi [36] explained the decreased sperm count in diabetic rats by the decrease in Sertoli cell glucose utilization affecting sperm development. Moreover, our results were consistent with Akondi, et al., [37] who reported a decrease in sperm parameters in diabetic rats. Furthermore, Fui, Dupuis [38] added that obesity, which is a major risk factor for T2DM, induced hypoandrogenemia and hypogonadotropic hypogonadism. Also, Alves, et al., [15] reported that diabetic patients may experience infertility and sexual dysfunction. On the contrary, Agbaje, et al., [18] stated that diabetic men had normal semen parameters. Also, Idris, et al., [17] found that LH and testosterone plasma levels were normal in diabetic rats while FSH level was increased and, they observed that diabetes did not alter the pituitary glands and Leydig cells functions, but, it affected the functions of Sertoli cell due to FSH receptors reduction. The discrepancy between these results and ours may be related to the difference in type and duration of diabetes induced. Also, in T2DM group, a significant negative correlation was reported between testicular function (serum testosterone, epididymal sperm count and motility) and each of BMI and HOMA-IR index which reflected decreased testicular function in T2DM. This result was in agreement with Sermondade, et al., [39] who declared that obesity affected the reproductive system of the male by semen quality degradation and endocrine system adverse effects. The effects of T2DM on testicular function were confirmed by the histopathological changes occurred in the rat testicular tissue from T2DM group. There was a decrease in both, the number of layers of spermatogenic cells and the mature sperms and the basement membrane was thick. These results were in agree with Lapolla, et al., [40] who reported that in diabetes mellitus, there was an increase in lipid peroxidation and an imbalance in carbohydrate metabolism which impaired testicular steroidogenic function and damaged testicular tissue. Also, Nah, Koh [16] confirmed that the effects of diabetes on testicular architecture and weight were due to the decline in testosterone serum levels which is essential for the normal growth of reproductive organs. Also, the results of this study declared a significant reduction in serum levels of FSH and LH in T2DM group when compared with the control one, but, a significant negative correlation was 
found between testicular function and serum levels of FSH and LH in the same studied group. This confirmed that T2DM may decrease testicular function through affecting secretion of $\mathrm{LH}$ and FSH. This was supported by Granado, et al., [41] who stated that insulin normally acted upon the anterior pituitary to regulate gonadotropin release which was disturbed in diabetic rats. This was also supported by Holdcraft and Braun [42] who declared that FSH is important to stimulate Sertoli cells to synthesize and secrete androgen-binding protein, which is essential to bind testosterone that is required for spermatid terminal differentiation. García, et al., [43] reported that the decrease in FSH level decreased production of stem cell factor, a Sertoli cell product, which is essential for Leydig cell and spermatogonia development and survival in adult rats. Also, Nah, et al., [16] found a reduction in $\mathrm{FSH}, \mathrm{LH}$ and testosterone serum levels as well as a decrease in sperm count and motility in diabetes. In the T2DM group, a significant decline in testicular SOD and CAT activity was reported in comparison to the control group which confirmed the presence of oxidative stress in T2DM, but, a significant positive correlation was found between testicular function and testicular SOD and CAT activity. This confirmed that T2DM may decrease testicular function through affecting activity of testicular SOD and CAT. This was supported by Akondi, et al., [37] and Vignera, et al., [44] who reported an increase incidence of infertility among diabetic males and the owed this to the increased oxidative stress in testes of such cases. This was also supported by Gobbo, et al., [45] who added that sperm head membrane was also highly sensitive to oxidative stress due to its high content of polyunsaturated fatty acid. Moreover, Akondi, et al., [37] declared that the oxidative stress was more with hyperglycemia due to excessive reactive oxygen species production and decreased activity of the antioxidant enzymes. Also, in this study, a significant increase in the proinflammatory cytokines, TNF $\alpha$ and IL-1 $\beta$, was reported in the T2DM group in comparison to the control one which indicated the presence of inflammation in T2DM. Also, in T2DM group, testicular function was negatively associated with serum levels of each of TNF $\alpha$ and IL-1 $\beta$. Thus, increased proinflammatory cytokines may be a mechanism by which testicular function is decreased in T2DM. This was supported by Baccetti, et al., [46] who owed the effects of diabetes on testicular function to local testicular reaction caused by the diabetic oxidative stress stimulating inflammatory cells and macrophages to secrete IL- $1 \beta$ and TNF $\alpha$ which affected both steroidogenesis and spermatogenesis.
On the other hand, in T2DM + Nesfatin group, a significant decrease in final BMI, HOMA-IR index, serum levels of glucose, insulin, TC and TG, but, a significant increase in serum level of HDL was found in comparison to the T2DM group which confirmed that administration of nesfatin- 1 to diabetic rats improved body weight and metabolic disturbances of T2DM. These results were supported by Palasz, et al., [27] who confirmed that nesfatin-1 treatment decreased body weight of obese rats. Also, Irannejad, et al., [3] and Iwona, et al., [47]reported that nesfatin-1 increased peripheral and hepatic insulin sensitivity decreasing gluconeogenesis and enhancing peripheral uptake of glucose. Moreover, Shimizu, et al., [7] found that nesfatin-1 injection decreased blood glucose in hyperglycemic mice. Furthermore, Yang, et al., [10] and Iwona, et al., [47] declared that injection of obese rats with nesfatin- 1 decreased hepatic gluconeogenesis. In addition, Ramesh, Mortazavi [48]added that nesfatin-1 regulated energy homeostasis through stimulation of glucagon-like peptide-1 secretion. It has demonstrated that the improvement in testicular function on treatment of diabetic rats with Nesfatin-1 was accompanied by an improvement in the histopathological features of rat testicular tissue from T2DM + Nesfatin group as there was a marked improvement in the number of layers of spermatogenic cells and the number of mature sperms. Also, the basement membrane becomes thinner in comparison to the T2DM group. Also, in T2DM + Nesfatin group, a significant rise in right testis weight, testicular SOD and CAT activity was found in comparison to the T2DM group which declared that Nesfatin- 1 has antioxidant activity in T2DM. These results were supported by Jiang, et al., [49] who found that Nesfatin- 1 decreased oxidative stress by its antioxidant and anti-inflammatory properties. Moreover, there was a significant decline in serum levels of TNF $\alpha$ and IL- $1 \beta$ in T2DM + Nesfatin group in comparison to the T2DM group which declared that Nesfatin- 1 has anti-inflammatory properties in T2DM. In agree with these results, Jiang, et al., [49] and Iwona, et al., [47] confirmed that nesfatin1 had anti-inflammatory activities. Also, Solmaz, et al., [23] reported that Nesfatin-1, through its antiinflammatory and antioxidant activities, improved the inflammatory condition during healing of a cutaneous wound in hyperglycemic rats. Furthermore, in T2DM + Nesfatin group, a significant increase in serum levels of FSH, LH, and testosterone, epididymal sperm count and motility was reported in comparison to the T2DM group which confirmed that Nesfatin-1 increased secretion of FSH and LH, and, improved testicular function in 
T2DM. These results were supported by GarcíaGaliano, et al., [4] who reported that Nesfatin-1 treatment significantly raised serum levels of LH and FSH in rats and hence improved testicular function. Also, García-Galiano, et al., [19] proved that Nesfatin- 1 peptide expression in testis was confined to Leydig and Sertoli cells which may declare the potential protective effects on testicular function through its regulation of testicular testosterone production and sperm development and maturation under metabolic stress. Moreover, Catak, et al., [50] reported that Nesfatin-1 was produced also by seminal gland epithelial cells and spermatocytes in the seminiferous tubules of the testes, and they added that it could be involved in the regulation of gonadal functions by regulation of both, energy homeostasis and gonadotropins secretion. Limitations to this study include, the sample size was small, large sample size is needed in further studies. Also, we examined all the parameters taken only after a short period of treatment, without evaluating long-term effects of Nesfatin1. Moreover, this study used an animal model of T2DM, thus the outcomes may be different from those in human.

\section{Conclusion:}

T2DM decreased testicular functions, spermatogenesis and steroidogenesis, through disturbing metabolic homeostasis, decreasing gonadotropins secretion, reducing testicular antioxidants activity and increasing proinflammatory cytokines. On the other hand, exogenous Nesfatin-1 treatment ameliorated testicular function changes in T2DM through controlling body weight, improving metabolic disturbances, increasing FSH and LH secretion, its antioxidant and its anti-inflammatory properties which can give a chance for a new line of treatment for reproductive complications of diabetes. These results need further studies to be confirmed. Also, additional studies are needed to assess the potential use of Nesfatin-1 as a protective target for T2DM testicular dysfunction.

\section{Acknowledgements:}

To Professor Kamal El-Kashish, Pathology Department, Zagazig Faculty of Medicine for achieving the histopathological part of this study.

\section{Conflict of interest:}

None to declare.

\section{References}

1- DARAMBAZAR G., et al.: Paraventricular NUCB2/ Nesfatin-1 is directly targeted by leptin and mediates its anorexigenic effect. Biochemical and biophysical research communications, 456 (4): p. 913-8, 2015.
2- TAN B.K., et al.: Decreased cerebrospinal fluid/plasma ratio of the novel satiety molecule, nesfatin-1/NUCB-2, in obese humans: Evidence of nesfatin-1/NUCB-2 resistance and implications for obesity treatment. The Journal of Clinical Endocrinology \& Metabolism, 96 (4): p. E669E673, 2011.

3- IRANNEJAD A., et al.: Association of peripheral nesfatin1 with early stage diabetic nephropathy. Pathophysiology, 24 (1): p. 17-22, 2017.

4- GARCÍA-GALIANO D., et al.: The anorexigenic neuropeptide, nesfatin-1, is indispensable for normal puberty onset in the female rat. Journal of Neuroscience, 30 (23): p. 7783-92, 2010.

5- XIA Q.R., et al.: Increased plasma nesfatin-1 levels may be associated with corticosterone, IL-6, and CRP levels in patients with major depressive disorder. Clinica Chimica Acta, 2018.

6- KHALILI S., et al.: NUCB2/Nesfatin-1: A Potent Meal Regulatory Hormone and its Role in Diabetes. Egyptian Journal of Medical Human Genetics, 2016.

7- SHIMIZU H., M. TANAKA and A. OSAKI: Transgenic mice overexpressing nesfatin/nucleobindin-2 are susceptible to high-fat diet-induced obesity. Nutrition \& Diabetes, 6 (3): p. e201, 2016.

8- RAMANJANEYA M., et al.: Identification of nesfatin1 in human and murine adipose tissue: A novel depotspecific adipokine with increased levels in obesity. Endocrinology, 151 (7): p. 3169-80, 2010.

9- ZHANG Z., et al.: Increased plasma levels of nesfatin-1 in patients with newly diagnosed type 2 diabetes mellitus. Experimental and clinical endocrinology \& diabetes, 120 (02): p. 91-5, 2012.

10- YANG M., et al.: Nesfatin-1 action in the brain increases insulin sensitivity through Akt/AMPK/TORC2 pathway in diet-induced insulin resistance. Diabetes, 61 (8): p. 1959-68, 2012.

11- WU D., et al.: Hypothalamic nesfatin-1/NUCB2 knockdown augments hepatic gluconeogenesis that is correlated with inhibition of mTOR-STAT3 signaling pathway in rats. Diabetes, 63 (4): p. 1234-47, 2014.

12- CHRISTIAN C.A. and S.M. MOENTER: The neurobiology of preovulatory and estradiol-induced gonadotropinreleasing hormone surges. Endocrine Reviews, 31 (4): p. 544-77, 2010

13- CASTELLANO J.M., et al.: Kisspeptins: Bridging energy homeostasis and reproduction. Brain Research, 1364: p. 129-38, 2010.

14- HAKIM P., H.A. SANI and M.M. NOOR: Effects of Gynura procumbens extract and glibenclamide on sperm quality and specific activity of testicular lactate dehydrogenase in streptozotocin-induced diabetic rats. Malaysian Journal of Biochemistry and Molecular Biology, 16 (2): p. 10-4, 2008.

15-ALVES M., et al.: Molecular mechanisms beyond glucose transport in diabetes-related male infertility. Biochimica et Biophysica Acta (BBA)-Molecular Basis of Disease, 1832 (5): p. 626-35, 2013. 
16- NAH W.H., et al.: Effect of Spirulina maxima on spermatogenesis and steroidogenesis in streptozotocin-induced type I diabetic male rats. Food chemistry, 134 (1): p. 1739, 2012.

17-IDRIS M.H.M., et al.: Protective role of Hibiscus sabdariffa calyx extract against streptozotocin induced sperm damage in diabetic rats. EXCLI Journal, 11: p. 659, 2012.

18- AGBAJE I., et al.: Insulin dependant diabetes mellitus: Implications for male reproductive function. Human Reproduction, 22 (7): p. 1871-7, 2007.

19- GARCÍA-GALIANO D., et al.: Cellular distribution, regulated expression, and functional role of the anorexigenic peptide, NUCB2/nesfatin-1, in the testis. Endocrinology, 153 (4): p. 1959-71, 2012.

20- MAGDY Y.M., et al.: Potential involvement of JNK1 repression in the hepatic effect of sitagliptin and metformin in rats subjected to high fat diet and chronic mild distress. Biomedicine \& Pharmacotherapy, 85: p. 22538, 2017.

21- REED M., et al.: A new rat model of type 2 diabetes: The fat-fed, streptozotocin-treated rat. Metabolism, 49 (11): p. 1390-14, 2000.

22- De BEM G.F., et al.: Euterpe oleracea Mart.(açaí) seed extract associated with exercise training reduces hepatic steatosis in type 2 diabetic male rats. The Journal of Nutritional Biochemistry, 52: p. 70-81, 2018.

23- SOLMAZ A., et al.: Nesfatin-1 improves oxidative skin injury in normoglycemic or hyperglycemic rats. Peptides, 78: p. 1-10, 2016.

24- LONG L., et al.: Hyperglycemia induced testicular damage in type 2 diabetes mellitus rats exhibiting microcirculation impairments associated with vascular endothelial growth factor decreased via PI3K/Akt pathway. Vol. 9. 2018.

25- FRIEDEWALD W.T., R.I. LEVY and D.S. FREDRICKSON: Estimation of the concentration of low-density lipoprotein cholesterol in plasma, without use of the preparative ultracentrifuge. Clinical chemistry, 18 (6): p. 499-502, 1972.

26- NAYAK Y., et al.: Antidiabetic activity of benzopyrone analogues in nicotinamide-Streptozotocin induced Type 2 diabetes in rats. The Scientific World Journal, 2014: p. 1-12, 2014.

27- PALASZ A., et al.: The potential role of the novel hypothalamic neuropeptides Nesfatin-1, phoenixin, spexin and kisspeptin in the pathogenesis of anxiety and anorexia nervosa. Neurochemistry international, 2017.

28- SCHLORFF E., K. HUSAIN and S. SOMANI: Dose and time dependent effects of ethanol on antioxidant system in rat testes. Alcohol, 18 (2): p. 203-14, 1999.

29- NARAYANA K., U.J.D. SOUZA and K.S. RAO: Effect of ribavirin on epididymal sperm count in rat. Indian journal of physiology and pharmacology, 46 (1): p. 97 101, 2002.

30- VEGA S., et al.: Sperm shape abnormality and urine mutagenicity in mice treated with niclosamide. Mutation Research/Genetic Toxicology, 204 (2): p. 26976, 1988.
31- KHAKI A., et al.: Beneficial effects of quercetin on sperm parameters in streptozotocin-induced diabetic male rats. Phytotherapy Research, 24(9): p. 1285-91, 2010.

32- NOVELLI E., et al.: Anthropometrical parameters and markers of obesity in rats. Laboratory Animals, 41 (1): p. 111-9, 2007.

33- MAHDIEH N., et al.: High level of intrafamilial phenotypic variability of non-syndromic hearing loss in a Lur family due to delE120 mutation in GJB2 gene. International Journal of Pediatric Otorhinolaryngology, 74 (9): p. 108991, 2010.

34- NAZIROGLU M., et al.: Protective effects of nanostructures of hydrated C60 fullerene on reproductive function in streptozotocin-diabetic male rats, 2011.

35- KIM S.T. and K.H. MOLEY: Paternal effect on embryo quality in diabetic mice is related to poor sperm quality and associated with decreased glucose transporter expression. Reproduction, 136 (3): p. 313-22, 2008.

36- HAMDEN K., et al.: Potential protective effect on key steroidogenesis and metabolic enzymes and sperm abnormalities by fenugreek steroids in testis and epididymis of surviving diabetic rats. Archives of physiology and biochemistry, 116 (3): p. 146-55, 2010.

37- AKONDI R.B., et al.: Protective effect of Rutin and Naringin on sperm quality in streptozotocin (STZ) induced type 1 diabetic rats. Iranian Journal of Pharmaceutical Research: IJPR, 10 (3): p. 585, 2011.

38- FUI M.N.T., P. DUPUIS and M. GROSSMANN: Lowered testosterone in male obesity: Mechanisms, morbidity and management. Asian Journal of Andrology, 16 (2): p. 223, 2014.

39- SERMONDADE N., et al.: Obesity and increased risk for oligozoospermia and azoospermia. Archives of Internal Medicine, 172(5): p. 440-2, 2012.

40- LAPOLLA A., D. FEDELE and P. TRALDI: Glycooxidation in diabetes and related diseases. Clinica chimica acta, 357 (2): p. 236-50, 2005.

41- GRANADO M., et al.: Ghrelin treatment protects lactotrophs from apoptosis in the pituitary of diabetic rats. Molecular and cellular endocrinology, 309 (1): p. 67-75, 2009.

42- HOLDCRAFT R.W. and R.E. BRAUN: Androgen receptor function is required in Sertoli cells for the terminal differentiation of haploid spermatids. Development, 131 (2): p. 459-67, 2004.

43- GARCÍA M.C., et al.: Role of ghrelin in reproduction. Reproduction, 133 (3): p. 531-40, 2007.

44- VIGNERA S., et al.: Diabetes mellitus and sperm parameters. Journal of andrology, 33(2): p. 145-53, 2012.

45- GOBBO M.G., et al.: Oxidative stress markers and apoptosis in the prostate of diabetic rats and the influence of vitamin C treatment. Journal of Cellular Biochemistry, 113 (7): p. 2223-33, 2012.

46- BACCETTI B., et al.: Insulin-dependent diabetes in men is associated with hypothalamo-pituitary derangement and with impairment in semen quality. Human Reproduction, 17 (10): p. 2673-7, 2002. 
47- IWONA P., et al.: Role of nesfatin-1 in the metabolism of skeletal tissues. Medycyna weterynaryjna, 74 (1): p. 6045-58, 2018.

48- RAMESH N., S. MORTAZAVI, and S. UNNIAPPAN: Nesfatin-1 stimulates glucagon-like peptide-1 and glucosedependent insulinotropic polypeptide secretion from STC1 cells in vitro. Biochemical and biophysical research communications, 462 (2): p. 124-30, 2015.
49- JIANG G., et al.: The protective effect of nesfatin-1 against renal ischemia-reperfusion injury in rats. Renal Failure, 37 (5): p. 882-9, 2015.

50- CATAK Z., et al.: Regulatory neuropeptides (ghrelin, obestatin and nesfatin-1) levels in serum and reproductive tissues of female and male rats with fructose-induced metabolic syndrome. Neuropeptides, 48 (3): p. 167-77, 2014. 


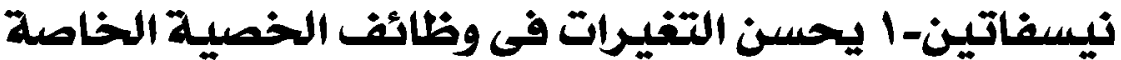

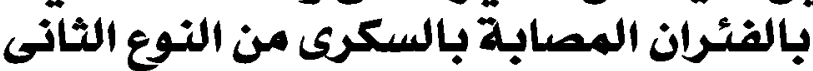

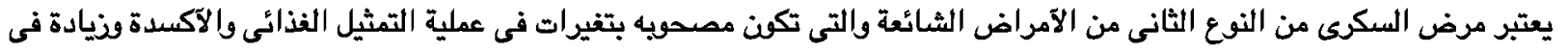

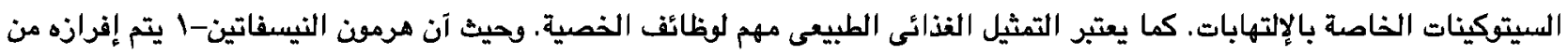

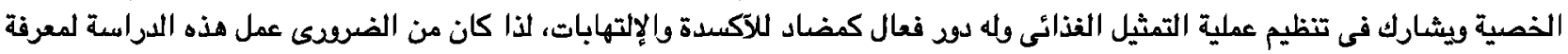

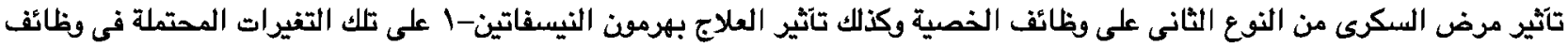
الخصية بالفئران المصابة بالسكرى من النوع النوع الثانى.

وفى هذه الدراسة تم تقسيم فئران التجارب المستخدمة إلى ثلالت مجموعات متساوية:

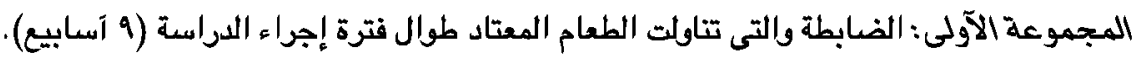

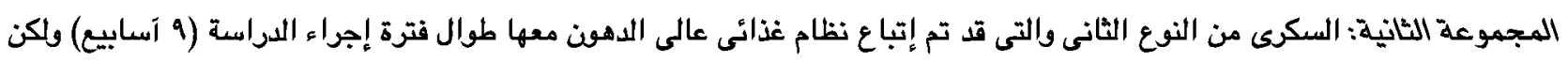

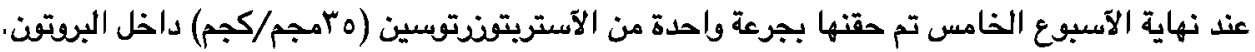

المجموعة الثالثة: السكرى من النوع الثانى والمعالجة بهرمون النسفاتين-1 ـ وفى هذه المجموعة تم إتباع نظام غذائى عالى الدهون معها طوال

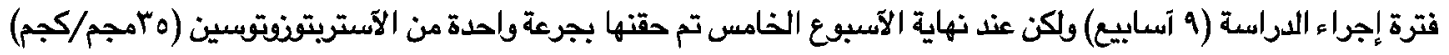

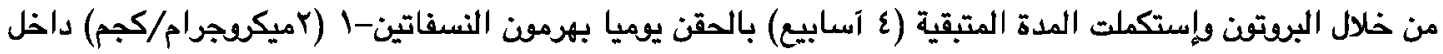

البرتون.

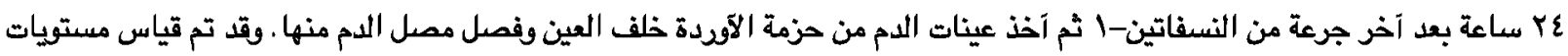

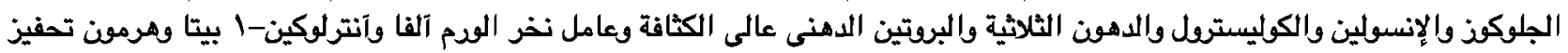

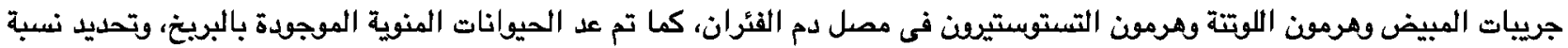

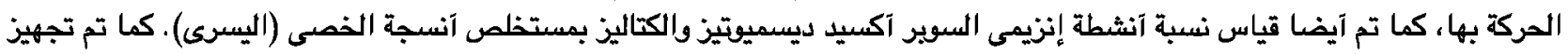

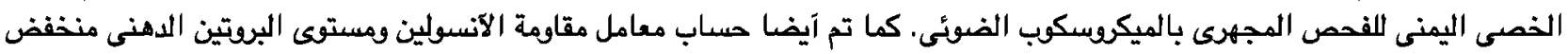

الكثافة بمعادلات خاصية.

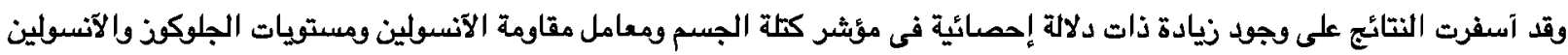

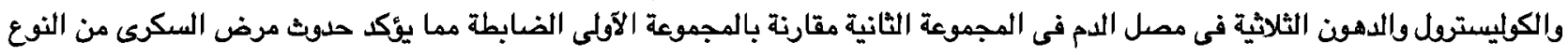

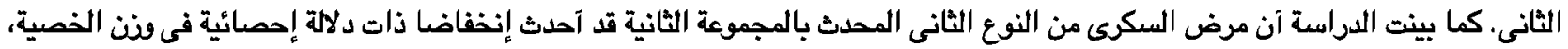

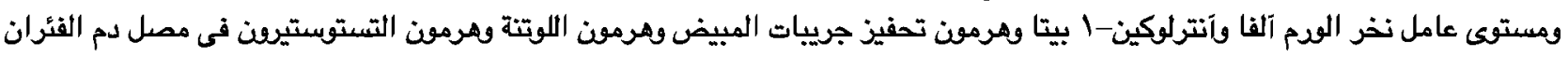

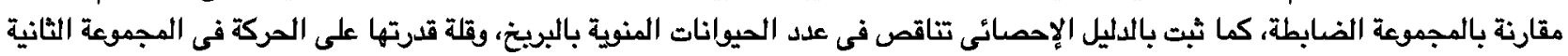

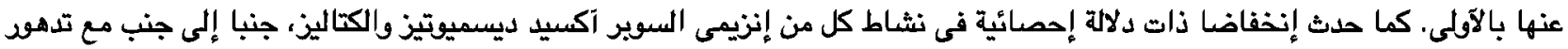
فى حالة آنسجة الخمية بالفصص الفجهرى بالمجموعة الثانية مقارنة بالمجموعة الآولى الضابطة.

ولقد وجد آن التداوى المزمن بالنسفاتين-1 فى المجموعة الثالثة آدى إلى تحسن ذات دلالة إحصائية فى جميع اليانات المذكمدة آعلاه مقارنة بالمجموعة الثانية.

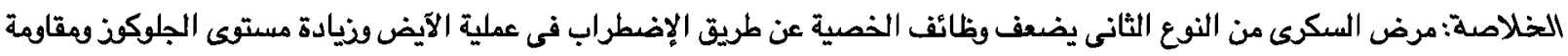

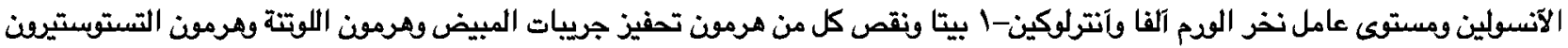

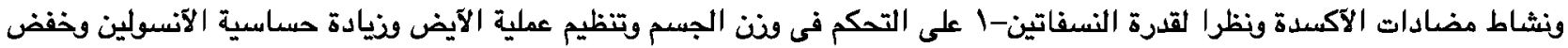

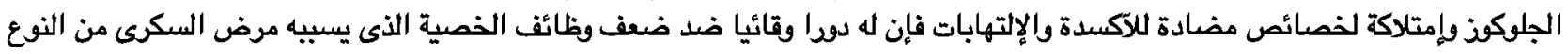

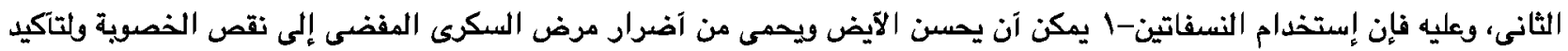
ذلك يستلزم المزيد من الدراسات. 